\title{
Determination of Heavy Metal Ions by Capillary Electrophoresis with Contactless Conductivity Detection after Field-amplified Sample Injection
}

\author{
Feng TAN, Bingcheng YANG, and Yafeng GuAN ${ }^{\dagger}$ \\ Department of Analytical Chemistry and Micro-Instrumentation, Dalian Institute of Chemical Physics, \\ Chinese Academy of Sciences, Dalian, 116012, China
}

\begin{abstract}
A method has been developed for determining of heavy metal ions by field-amplified sample injection capillary electrophoresis with contactless conductivity detection. The effects of the $2-N$-morpholinoethanesulfonic acid/histidine (MES/His) concentration in the sample matrix, the injection time and organic additives on the enrichment factor were studied. The results showed that MES/His with a low concentration in the sample matrix, an increase of the injection time and the addition of acetonitrile improved the enrichment factor. Four heavy metal ions $\left(\mathrm{Zn}^{2+}, \mathrm{Co}^{2+}, \mathrm{Cu}^{2+}\right.$ and $\left.\mathrm{Ni}^{2+}\right)$ were dissolved in deionized water, separated in a $10 \mathrm{mM}$ MES/His running buffer at $\mathrm{pH} 4.9$ and detected by contactless conductivity detection. The detection sensitivity was enhanced by about three orders of magnitude with respect to the non-stacking injection mode. The limits of detection were in the range from $5 \mathrm{nM}\left(\mathrm{Zn}^{2+}\right)$ to $30 \mathrm{nM}\left(\mathrm{Cu}^{2+}\right)$. The method has been used to determine heavy metal ions in tap water.
\end{abstract}

(Received February 10, 2005; Accepted March 8, 2005)

\section{Introduction}

Capillary electrophoresis (CE) for the analysis of ionic compounds is even-more concerned due to advantages of high resolution, rapid speed and small sample consumption, ${ }^{1-3}$ where conductivity detection is a very good selection method for moderate sensitivity and easy selection of a background electrolyte compared to the indirect UV-absorption detection usually used. Contact conductivity detection in $\mathrm{CE}$ has the disadvantages of contamination of the detection electrodes when samples containing complicated matrixes are analyzed, and interference of the separation high voltage with the detection signal, since the electrodes are in direct physical contact with electrolyte solutions. Capacitively coupled contactless conductivity detection $\left(\mathrm{C}_{4} \mathrm{D}\right)^{4,5}$ used a very simple detection cell and overcame the disadvantages mentioned above. Hauser ${ }^{6}$ demonstrated a high-voltage $\mathrm{C}_{4} \mathrm{D}$, which achieved limits of detection (LODs) on the order of $50 \mathrm{nM}$ for alkali, alkaline earth metal and ammonium ions, and $1-5 \mu \mathrm{M}$ for heavy metal ions $\left(\mathrm{Zn}^{2+}, \mathrm{Co}^{2+}, \mathrm{Cu}^{2+}\right.$ and $\left.\mathrm{Ni}\right)$ by indirect detection.

The analysis of trace heavy metal ions has been gaining much attention in environmental samples. Although spectral analysis, such as atomic absorption spectrometry (AAS), ${ }^{7-9}$ inductively coupled plasma-atomic emission spectrometry (ICP-AES) $)^{10-13}$ and inductively coupled plasma mass spectrometry (ICPMS), ${ }^{14,15}$ are standard methods for analysis of metal elements, $\mathrm{CE}$ as a good alternative is becoming even-more recognized. In order to obtain efficient detection sensitivity, many preconcentration techniques are usually adapted in trace analysis. Burgi and Chien ${ }^{16,17}$ demonstrated the field-amplified

$\dagger$ To whom correspondence should be addressed.

E-mail: kfguan@mail.dlptt.ln.cn sample injection (FASI) technique for on-line preconcentration of analytes in CE. In FASI, samples are prepared in a lowconductivity buffer and injected electrokinetically into a capillary containing a high-conductivity running buffer. Because of the low conductivity of the sample, a high electricfield strength is established at the capillary inlet. A large amount of sample ions migrate into the capillary and stack at the boundary between the sample zone and the running buffer. An enhancement of detection sensitivity about several hundreds or even thousands times is generally achieved by FASI, ${ }^{18-21}$ which provides a convenient on-line preconcentration method for the analysis of trace or ultra-trace analytes in environmental samples. Cheng ${ }^{22}$ reported a method of on-line chemiluminescence detection with field-amplified injection in $\mathrm{CE}$, where the sensitivity was improved by approximately six orders of magnitude, and sub-fM level cobalt detection was achieved. Isoo ${ }^{23}$ achieved an LOD of 3.8 ppt for $\mathrm{Co}^{2+}$ with UVdetection by sweeping in conjunction with FASI, where a 140000-fold improvement for $\mathrm{Co}^{2+}$ ions was realized. In this paper, we describe the analysis of heavy metal ions by using FASI-CE with $\mathrm{C}_{4} \mathrm{D}$ detection. The detection sensitivity is enhanced about three orders of magnitude with respect to the non-stacking injection mode and LODs of $\mathrm{nM}$ are achieved.

\section{Experimental}

\section{Instrumentation}

A homemade CE system was used for all experiments. It consisted of two high-voltage power supply $(0-20 \mathrm{kV}$ and 0 $30 \mathrm{kV}$, Dongwen, China) units, one $(0-30 \mathrm{kV})$ for $\mathrm{CE}$ separation while the other for injection, and a fused-silica capillary $\left(65 \times 50 \mu \mathrm{m}\right.$ i.d. $\times 375 \mu \mathrm{m}$ o.d., $L_{\text {detector }}=51 \mathrm{~cm}$, Yongnian, China). A new capillary was treated by rinsing with 


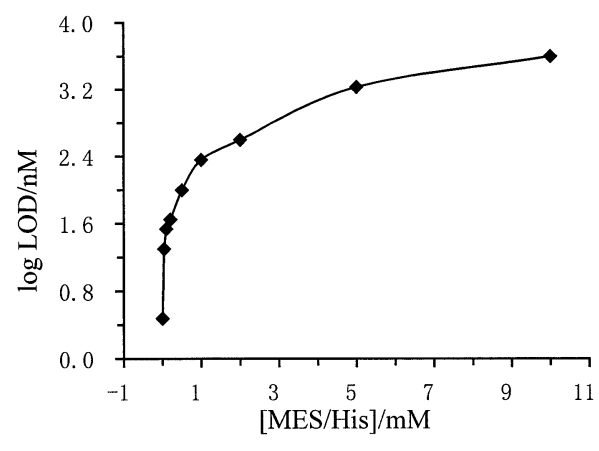

Fig. 1 Effect of the concentration of MES/His in sample solutions on the limit of detection of $\mathrm{Zn}^{2+}(\mathrm{nM})$. Separation electrolyte, $10 \mathrm{mM}$ $\mathrm{MES} / \mathrm{His}$ at $\mathrm{pH} 4.9$ adjusted by $5 \%$ acetic acid; separation voltage, 20 $\mathrm{kV}$; sample injection, $5 \mathrm{kV}$ for $30 \mathrm{~s} ; \mathrm{C}_{4} \mathrm{D}, 200 \mathrm{kHz}, 220 \mathrm{~V}_{\mathrm{p}-\mathrm{p}}$.

$1 \mathrm{M}$ hydrochloric acid and $1 \mathrm{M}$ sodium hydroxide solutions for $3 \mathrm{~min}$ in turn, followed by deionized water for $5 \mathrm{~min}$, and finally by running buffer for $3 \mathrm{~min}$. The capillary was rinsed with the buffer for $1 \mathrm{~min}$ before each injection. Kefen chromstation (Scien-Tech Instrument Inc., Dalian, China) was used for data acquisition.

The electrodes of $\mathrm{C}_{4} \mathrm{D}$ were two identical stainless-steel tubes (400 $\mu \mathrm{m}$ i.d. and $700 \mu \mathrm{m}$ o.d.) $5 \mathrm{~mm}$ in length, placed $1 \mathrm{~mm}$ apart from each other. A thin-grounded copper plane with a 0.4 $\mathrm{mm}$ diameter central hole, through which the separation capillary was passed, was placed between the electrodes to minimize the coupling capacitance through the air between the electrodes. The electronic circuitry of the $\mathrm{C}_{4} \mathrm{D}$ was analogous to that described in Ref. 5 except that a high-voltage excitation source was used, which comprised a home-made transformer and a EE1641B1 function generator (Xinlian Electronic Corp., Nanjing, China).

\section{Reagents and method}

All reagents used were of analytical grade, and high-purified water from a Milli Q (Millipore, Bedford, MA, USA) was used throughout. Stock solutions $(20 \mathrm{mM})$ of heavy metal ions were prepared from their nitrate $\left(\mathrm{Ni}^{2+}, \mathrm{Co}^{2+}\right)$, sulfate $\left(\mathrm{Cu}^{2+}\right)$ and acetate $\left(\mathrm{Zn}^{2+}\right)$ salts. The sample solutions were prepared fresh before use by dilution of stock solutions with the water. 2- $\mathrm{N}$ morpholinoethanesulfonic acid (MES) (Biomo, USA) and histidine (His) (Shanghai Chemical Reagent Corp., China) were purchased and used. Fresh electrolyte solutions were prepared daily by mixing $0.1 \mathrm{M}$ MES and His stock solution and degassed in an ultrasonic bath and subsequently filtered with $0.45 \mu \mathrm{m}$ syringe filters before use; $5 \%$ acetic acid was used to adjust the $\mathrm{pH}$ of the electrolyte. To avoid contamination of ions from the glass vessel, plastic vials were used for filling the sample solutions. The vials were washed with hydrochloride acid, followed by high-purified water before use. The sample injection time was $5-60 \mathrm{~s}$ at $5 \mathrm{kV}$. The separation voltage of CE was kept at $20 \mathrm{kV}$ throughout the study. All experiments were carried out at $25 \pm 1^{\circ} \mathrm{C}$.

\section{Results and Discussion}

Effect of the concentration of MES/His in the sample solution

The stacking efficiency in FASI can be described by the following equation: ${ }^{21}$

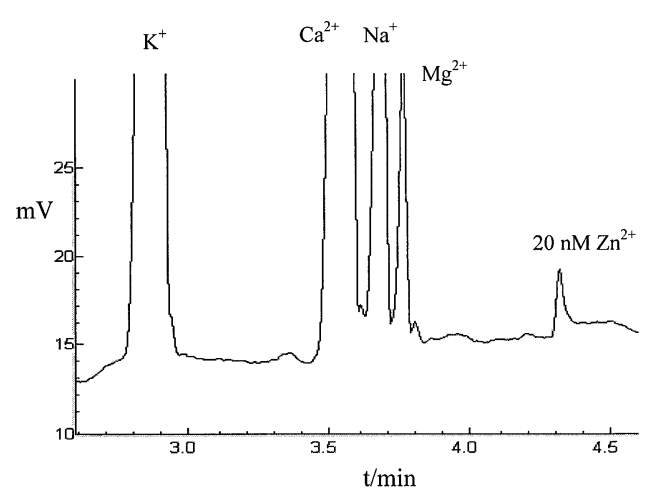

Fig. 2 Electropherogram of $20 \mathrm{nM} \mathrm{Zn}{ }^{2+}$. The conditions are the same as in Fig. 1.

$$
E_{\mathrm{s}}=\frac{E_{1} \mu_{1}}{E_{2} \mu_{2}}
$$

where $E_{\mathrm{s}}$ is the stacking efficiency, $E_{1}$ and $\mu_{1}$ are the electric field strength and the effective electrophoretic mobility of the analytical ion in the sample zone; $E_{2}$ and $\mu_{2}$ are the corresponding parameters in the buffer zone. According to Eq. (1), the larger in the difference of the electric field strength between the sample and the buffer zone, the larger in the stacking efficiency, which indicates that a sample solution with low conductivity should be prepared for high stacking efficiency and detection sensitivity. In this study, heavy-metal ions were prepared in a buffer containing 0-10 mM MES/His electrolyte to demonstrate the effect of the conductivity of the sample buffer on the stacking efficiency. Figure 1 shows that the effect of the MES/His concentration on LOD of $\mathrm{Zn}^{2+}$, is similar to that in Ref. 22. It can be seen that the LOD in pure water and a buffer of low concentration is lower than that in a high electrolyte concentration, and that the LOD in pure water is three orders of magnitude $\left(1.3 \times 10^{3}\right)$ lower than that in 10 $\mathrm{mM}$ MES/His buffer. Figure 2 is electropherogram of $20 \mathrm{nM}$ $\mathrm{Zn}^{2+}$ prepared in water. It can be seen that the peak of the $\mathrm{Zn}^{2+}$ is comparatively sharp, which indicates that the analyte can be stacked in a narrow zone. The calculated LOD of $\mathrm{Zn}^{2+}$ is $5 \mathrm{nM}$, based on a signal-to-noise ratio of 3. Similar results were also obtained for $\mathrm{Co}^{2+}, \mathrm{Cu}^{2+}$ and $\mathrm{Ni}^{2+}$. The enhancement of detection sensitivity was over $10^{3}$ for $\mathrm{Co}^{2+}$ and $\mathrm{Ni}^{2+}$, and 800 for $\mathrm{Cu}^{2+}$.

\section{Effect of the injection time}

The influence of the injection time on the enrichment factor (detection sensitivity) is shown in Fig. 3. As expected, the peak height is proportional to the injection time in the range from 5 to $60 \mathrm{~s}$, and the separation efficiency (height plate) keeps almost constant below $50 \mathrm{~s}$. A further increase in the injection time causes peak broadening, and thus reduces the separation efficiency. Hence, subsequent studies are carried out below an injection time of $50 \mathrm{~s}$

\section{Effect of the concentration of the running buffer}

According to the basic theory of FASI, an increase in the conductivity (concentration) of the running buffer results in a larger conductivity difference between the buffer and the sample zone, and a higher stacking efficiency can be achieved, and thus higher sensitivity; however, a higher running buffer concentration reduces, the conductivity difference between the $\mathrm{Zn}^{2+}$ and $\mathrm{Co}^{2+}$ ions and the buffer, and thus lower the peaks. 


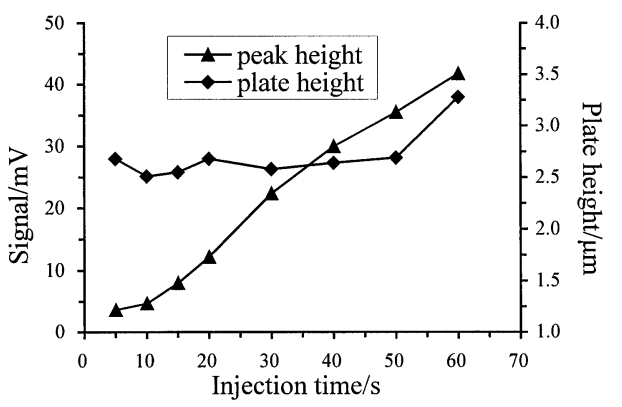

Fig. 3 Effect of the injection time on the peak height and the plate

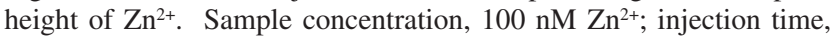
from $5 \mathrm{~s}$ to $60 \mathrm{~s}$. All other conditions are the same as in Fig. 1.

The two effects on the detection sensitivity conflict. In our experiments, we found that the peak heights of $\mathrm{Zn}^{2+}$ and $\mathrm{Co}^{2+}$ were reduced when the concentration of the running buffer was increased from $5 \mathrm{mM}$ to $15 \mathrm{mM}$, which showed that the effect of the conductivity on the sensitivity was dominant. Because the $\mathrm{Ni}^{2+}$ and $\mathrm{Cu}^{2+}$ ions produce negative response peaks, which indicates that the two effects are accordant, we found an increase in the peaks when the concentration of the buffer was increased. It is a compromise to select a $10 \mathrm{mM} \mathrm{MES/His}$ running buffer for the simultaneous analysis of the four heavy metal ions.

\section{Effect of the addition of acetonitrile}

The addition of an organic solvent into the sample matrix can decrease the conductivity and viscosity of the sample matrix, and thus improve the stacking efficiency due to an increase of the electric field strength and the electrophoretic motilities of analytes in the sample zone. By adding 15\% acetonitrile into the sample matrix (water), a 1.5-fold sensitivity enhancement was achieved. A higher concentration of acetonitrile was not used due to an increase of the migration time of the ions.

\section{Peaks of light ions}

There are always several large peaks before the peak of $\mathrm{Zn}^{2+}$ in Fig. 2, which are response peaks of $\mathrm{K}^{+}, \mathrm{Na}^{+}, \mathrm{Ca}^{2+}$ and $\mathrm{Mg}^{2+}$ from the used water. The $\mathrm{C}_{4} \mathrm{D}$ combined with FASI can achieve the LODs of $\mathrm{nM}$ or sub-nM to these light ions, which are lower than the background concentration of them in the used purified water. It is possible for the $\mathrm{C}_{4} \mathrm{D}$ with FASI to be used to analyze trace or ultra-trace alkali and alkaline metal ions in special samples if highly purified background electrolyte is used.

\section{Simultaneous analysis of four heavy metal ions}

Figure 4 is an electropherogram of four metal ions $\left(\mathrm{Zn}^{2+}, \mathrm{Co}^{2+}\right.$ $\mathrm{Cu}^{2+}$ and $\mathrm{Ni}^{2+}$ ) that were prepared in purified water and separated in CE by FASI in $10 \mathrm{mM}$ MES/His running buffer at $\mathrm{pH}$ 4.9. The four ions were completely separated in less than 7 min. Figure 4 shows that the $\mathrm{Zn}^{2+}$ and $\mathrm{Co}^{2+}$ produced a positive response, but the $\mathrm{Cu}^{2+}$ and $\mathrm{Ni}^{2+}$ yielded negative peaks, which indicates that the latter have a smaller conductivity than the buffer. It is obvious that the peak of $\mathrm{Ni}^{2+}$ is much wider than those of the other ions; this phenomenon can also be seen in Ref. 6 (in Fig. 4). We can therefore draw that the widening of the $\mathrm{Ni}^{2+}$ peak is not attributed to the FASI process, but to a stronger interaction of $\mathrm{Ni}^{2+}$ with hydroxyls on the inner wall of the separation capillary.

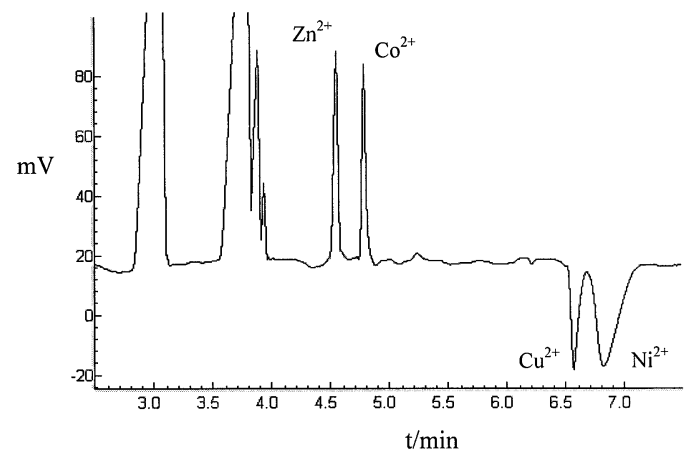

Fig. 4 Electropherogram of four heavy metal ions. Conditions: 500 $\mathrm{nM}$ metal ions, except for $\mathrm{Zn}^{2+}(100 \mathrm{nM})$; electrolyte, $10 \mathrm{mM}$ MES/His-15\% acetonitrile at $\mathrm{pH}$ 4.9. All other conditions are the same as in Fig. 1.

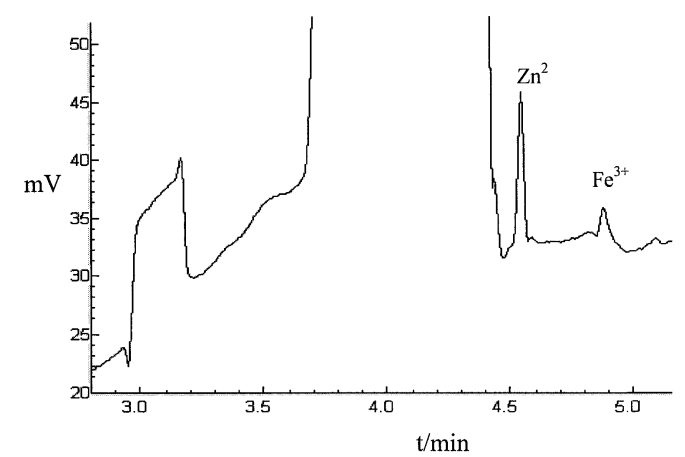

Fig. 5 Electropherogram of metal ions in tap water upon being diluted 10-fold. The conditions are the same as in Fig. 4.

\section{Analytical characteristics}

Under the optimized conditions, replicate analyses of the sample ions were carried out. The LODs and relative standard deviations (RSDs) of the migration time $\left(t_{\mathrm{s}}\right)$, peaks height $(h)$ and peaks area $(S)$ are given in Table 1 . The method shows a good linearity relationship between the peak area and the sample concentration, as can be seen from Table 1 .

\section{Analysis of real sample by the presented method}

The developed method was applied to the determination of trace metal ions in a tap water sample. Figure 5 is the electropherogram of diluted 10 -fold tap water by FASI. The calibration results showed that the water sample contained $\mathrm{Zn}^{2+}$ $(7.7 \mu \mathrm{M})$; no $\mathrm{Co}^{2+}, \mathrm{Cu}^{2+}$ or $\mathrm{Ni}^{2+}$ was found. The high peak before $\mathrm{Zn}^{2+}$ covered the peaks of $\mathrm{Na}^{+}, \mathrm{Ca}^{2+}, \mathrm{Mg}^{2+}$.

\section{Conclusions}

This study demonstrates that combining $\mathrm{C}_{4} \mathrm{D}$ with FASI greatly improves the detection sensitivity (over 1000-fold) and without any loss of the separation efficiency (within an injection time of $50 \mathrm{~s}$ ). The stacking efficiency in FASI strongly depends on the concentration of MES/His in the sample matrix. The increase in the injection time and the addition of acetonitrile can improve the detection sensitivity. The separation of $\mathrm{Zn}^{2+}, \mathrm{Co}^{2+}, \mathrm{Cu}^{2+}$ and $\mathrm{Ni}^{2+}$ was completed in $10 \mathrm{mM}$ MES/His running buffer at $\mathrm{pH}$ 4.9 and detected by $\mathrm{C}_{4} \mathrm{D}$; LODs at the $\mathrm{nM}$ level were achieved. The method has been used for the analysis of heavy metal ions in tap water 
Table 1 Limits of detection (LODs) and linearity range of sample ions, and relative standard deviations (RSDs, concentration: 500 nM except for $\left.100 \mathrm{nM} \mathrm{Zn}^{2+}\right)$ of the migration time $\left(t_{\mathrm{s}}\right)$, peak height $(h)$ and peak area $(S)(n=6)$

\begin{tabular}{|c|c|c|c|c|c|c|}
\hline \multirow{2}{*}{ Sample } & \multicolumn{3}{|c|}{ RSD, $\%$} & \multirow{2}{*}{$\mathrm{LOD} / \mathrm{nM}$} & \multirow{2}{*}{ Linearity range/nM } & \multirow{2}{*}{ Correlation coefficient } \\
\hline & $t_{\mathrm{s}} / \mathrm{min}$ & $h / \mathrm{mV}$ & $S$ & & & \\
\hline $\mathrm{Zn}^{2+}$ & $0.80(4.50)$ & $2.88(7.13)$ & 2.14 & 5 & $5-1000$ & 0.999 \\
\hline $\mathrm{Co}^{2+}$ & $0.91(4.72)$ & $3.30(7.29)$ & 2.08 & 10 & $10-1000$ & 0.998 \\
\hline $\mathrm{Cu}^{2+}$ & $1.37(6.44)$ & $3.16(3.63)$ & 1.38 & 30 & $30-1000$ & 0.998 \\
\hline $\mathrm{Ni}^{2+}$ & $1.46(6.68)$ & $4.13(4.52)$ & 5.58 & 15 & $15-1000$ & 0.997 \\
\hline
\end{tabular}

\section{Acknowledgements}

This work was supported by the National Natural Science Foundation of China (Contract No. 29925514 and No. 20227501), and Youth Science Foundation of Dalian Institute of Chemical Physics (Contract No. DICP S200304).

\section{References}

1. N. Avdalovic, C. A. Pohl, R. D. Rocklin, and J. R. Stillian, Anal. Chem., 1993, 65, 1470.

2. P. R. Haddad, P. Doble, and M. Macka, J. Chromatogr., A, 1999, 856, 145.

3. A. J. Zemann, TrAC, Trends Anal. Chem., 2001, 20, 346.

4. A. J. Zemann, E. Schnell, D. Volgger, and G. K. Bonn, Anal. Chem., 1998, 70, 563.

5. J. A. F. da Silva and C. L. do Lago, Anal. Chem., 1998, 70, 4339.

6. J. Tanyanyiwa and P. C. Hauser, Electrophoresis, 2002, 23, 3781.

7. M. C. Yebra-Biurrun, A. Moreno-Cid, and L. Puig, Anal. Chim. Acta, 2004, 524, 73.

8. B. F. Reis, M. Knochen, G. Pignalosa, N. Cabrera, and J. Giglio, Talanta, 2004, 64, 1220.

9. P. Bermejo-Barrera, A. Moreda-Piñeiro, and A. BermejoBarrera, Talanta, 2001, 57, 969.
10. S. Motomizu, K. Jimanee, and M. Oshima, Anal. Chim. Acta, 2003, 499, 149.

11. K. S. Rao, T. Balaji, T. P. Rao, Y. Babu, and G. R. K. Naidu, Spectrochim. Acta, Part B, 2002, 57, 1333.

12. S. G. Tuncel, S. Yenisoy-Karakas, and A. Dogangün, Talanta, 2004, 63, 273.

13. J. M. Jurado, A. Alcázar, F. Pablos, M. J. Martín, and A. G. González, Talanta, 2004, 63, 297.

14. E. Skrzydlewska, M. Balcerzak, and F. Vanhaecke, Anal. Chim. Acta, 2003, 479, 191.

15. E. Vassileva and C. R. Quétel, Anal. Chim. Acta, 2004, 519,79 .

16. R. L. Chien and D. S. Burgi, J. Chromatogr., 1991, 559, 153.

17. R. L. Chien and D. S. Burgi, J. Chromatogr., 1991, 559, 141.

18. C. X. Zhang and W. Thormann, Anal. Chem., 1996, 68, 2523.

19. B. Jung, R. Bharadwaj, and J. G. Santigo, Electrophoresis, 2003, 24, 3476.

20. C. X. Zhang and W. Thormann, Anal. Chem., 1998, 70, 540.

21. S. A. Leung and A. J. de Mello, J. Chromatogr., A, 2002, 979, 171.

22. Y. M. Liu, E. B. Liu, and J. K. Cheng, J. Chromatogr., A, 2001, 939, 91.

23. K. Isoo and S. Terabe, Anal. Chem., 2003, 75, 6789. 